\title{
Cross-cultural adaptation, factor structure, and evidence of reliability of the Smartphone Addiction Scale in Brazil
}

\author{
Paulo G. Laurence, (iD Alexandre O. Serpa, iD Helena S. Cunha Lima, Helen O. Mavichian, \\ Elizeu C. Macedo iD
}

Programa de Pós-Graduação em Distúrbios do Desenvolvimento, Laboratório de Neurociência Cognitiva e Social, Centro de Ciências Biológicas e da Saúde, Universidade Presbiteriana Mackenzie, São Paulo, SP, Brazil.

\begin{abstract}
Objective: To translate, adapt, and examine the factor structure and internal consistency of a Brazilian Portuguese version of the Smartphone Addiction Scale (SAS-BR) among university students. Methods: The SAS was translated and adapted for use with Brazilian samples. The resulting instrument (SAS-BR) was then administered to 356 college students. Parallel analysis was used to explore the maximum number of dimensions that underlie the assessment, and data modeling was undertaken using exploratory multidimensional item response theory (E-MIRT). The reliability of the SAS-BR was tested by computing McDonald's omega $(\omega)$ and Cronbach's alpha $(\alpha)$ coefficients.

Results: Parallel analysis revealed a maximum of six factors. E-MIRT analysis revealed that a fivefactor model was the best fit for the data. The five emergent factors were salience, positive anticipation, cyberspace-oriented relationship, preoccupation with smartphone, and physical symptoms; these factors together explained $50 \%$ of the variance. Confirmatory factor analysis, conducted using data from a second sample, replicated the five-factor structure. The internal consistency of the scale was found to be strong.

Conclusion: The emergent factor structure of the SAS-BR was found to be similar to that of previous adaptations of this instrument for other Western countries.
\end{abstract}

Keywords: Mobile phone; cell phone; addictive behavior; social network; Brazil

\section{Introduction}

The term "smartphone addiction" has been used to refer to the overuse of smartphones, given its characteristics similar to those of substance dependence. ${ }^{1}$ However, the term "addiction" is now being called into question, with many authors preferring "problematic smartphone use," since there is a lack of characteristics to sustain that smartphone overuse can be an addiction. ${ }^{2}$ The study of problematic smartphone use is becoming more relevant as new evidence emerges linking this condition with several health concerns,${ }^{2}$ including correlations with higher stress, higher depression symptoms, higher anxiety symptoms, and lower self-esteem. ${ }^{3,4}$

The Smartphone Addiction Scale (SAS) was created to assess behavioral patterns of smartphone use. It consists of 33 items, each of which requires responses to be recorded on a six-point Likert scale. Composite scores, obtained from the sum of individual item scores, can range from 33 to 198 points. ${ }^{5}$ The SAS has been used worldwide to identify and study behaviors related to problematic smartphone usage in countries such as China, ${ }^{6}$ Korea, ${ }^{5,7}$ Turkey, ${ }^{8,9}$ Malaysia, ${ }^{10}$ Morocco, ${ }^{11}$ and Romania. ${ }^{12}$

Correspondence: Paulo G. Laurence, Laboratório de Neurociência Cognitiva e Social, Centro de Ciências Biológicas e da Saúde, Universidade Presbiteriana Mackenzie, Rua Piauí, 181, $10^{\circ}$ andar, CEP 01241-001, São Paulo, SP, Brazil.

E-mail: p.laurence@ hotmail.com

Submitted Nov 07 2019, accepted Feb 11 2020, Epub Jun 152020.
The original version of the SAS, which was developed in South Korea, consists of six factors: daily-life disturbances, positive anticipation, withdrawal, cyberspaceoriented relationship, overuse, and tolerance. The internal consistency of this scale was measured using Cronbach's alpha $(\alpha=0.97)$, which was indicative of strong reliability. ${ }^{5}$ Subsequent studies that translated the SAS into different languages and validated these versions in different cultures have reported excellent internal consistency coefficients. However, they have also reported a few problems pertaining to the factor validity of the SAS. ${ }^{12}$ For example, the Turkish version was found to consist of seven factors: disturbing daily life and tolerance; withdrawal symptoms; positive anticipation; cyberspace-oriented relationship; overuse; social network dependence; and physical symptoms. The social network dependence factor compounded of two items that belonged to the cyberspace-oriented relationship factor of the original SAS, while the items subsumed by the physical symptoms factor belonged to the daily-life disturbances factor of the original assessment. The internal consistency of this scale (Cronbach's $\alpha=0.95)$ was found to be very high. ${ }^{9}$ The Malay and Arabic (validated in Morocco) versions were found to consist of

How to cite this article: Laurence PG, Serpa AO, Cunha Lima HS, Mavichian HO, Macedo EC. Cross-cultural adaptation, factor structure, and evidence of reliability of the Smartphone Addiction Scale in Brazil. Braz J Psychiatry. 2020;42:608-616. http://dx.doi.org/ 10.1590/1516-4446-2019-0778 
the same six factors that undergird the original SAS. However, the items that these factors subsumed were different from those of the original assessment. In the Arabic version, "overuse" was renamed "alleviation of negative emotions" because some of the items that belonged to the tolerance factor loaded onto the overuse factor. The internal consistencies of both versions of the assessment were found to be good ( $\alpha=0.94$ for both). ${ }^{10,11}$ Finally, the Romanian version of the SAS was found to consist of five factors: preoccupation with smartphone, daily-life disturbances, positive anticipation, cyberspace-oriented relationships, and overuse. The authors used McDonald's omega $(\omega)$ to measure the internal consistency of the scale, and the resulting value was indicative of strong reliability $(\omega=0.86)^{12}$

It transpires that the SAS has a problematic factor structure. Thus, there is a need for new studies that examine the differential functioning of the factor structure of the SAS across samples that belong to different cultures and speak different languages. Assessment of reliability and validity of the SAS has primarily been undertaken in Asian and European countries. Thus, the generalizability of these findings to other (e.g., Latin American) countries should be viewed cautiously.

Smartphone use is increasing in Brazil, ${ }^{13}$ but mental health professionals who work with individuals with problematic smartphone use only have a short scale ${ }^{14}$ and a scale based on internet compulsion ${ }^{15}$ to screen for this condition. Therefore, this study aimed to examine the factor structure and internal consistency of a Brazilian version of the Smartphone Addiction Scale (SAS-BR) among university students. To the best of our knowledge, there has been no past attempt to validate the full SAS in Brazil, although the short version has already been validated in the country. ${ }^{14}$ However, the short version does not consist of subfactors; instead, it yields a single composite score. Consequently, it does not allow one to identify the specific domain of problematic smartphone use that an individual may be struggling with. Furthermore, a Smartphone Dependency Scale ${ }^{15}$ was created in Brazil based on the compulsive internet scale, but internet dependency is theoretically distinct from smartphone dependency/addiction/problematic use. The first could be compared to an alcoholic beverage, while the second is analogous to the glass holding the alcoholic beverage, ${ }^{2}$ creating confusion as to whether the scale ultimately measures problematic smartphone use or internet addiction. Thus, adaptation of the full SAS, based as it is on theories of problematic smartphone use, is of crucial importance. One final relevant aspect of adaptation of this scale is that it will provide new inputs for the theoretical framework of problematic smartphone use, which is undergoing many changes due to conflicting evidence.

New evidence has emerged indicating that smartphone usage scales such as the SAS do not measure userelated behaviors (i.e., screen time, pickups). ${ }^{16,17}$ On the other hand, as pointed out by past research, ${ }^{2}$ screen time and pickups are not good measures of problematic smartphone use. Screen time alone does not capture what a person is doing with the smartphone. For example, if a user works or reads books on their smartphone, screen time will be high without necessarily representing problematic smartphone use. It is thus more important to know what one does on a smartphone rather than usage time alone; this requires the use of specific scales and tests. Evidence of reliability about the underlying structure of tests of symptoms or behaviors associated with non-established mental conditions, such as problematic smartphone use, could improve the knowledge base and contribute to a better understanding of the nosology of these conditions, as exemplified by DSM development history. ${ }^{18}$

\section{Methods}

\section{Participants}

Two samples were used in the present study. The data obtained from the first and second samples were used to conduct classical factor analysis, exploratory multidimensional item response theory (E-MIRT) analysis, and confirmatory factor analysis, respectively. The first sample consisted of 356 university students (women $=73 \%$ ) who were recruited from São Paulo, Brazil. Their ages ranged from 18 to 38 years (mean $[\mathrm{M}]=21.97$, standard deviation $[S D]=3.49)$. All participants were undergraduate students at the time of the study, most in law $(45.4 \%)$ and psychology $(23.8 \%) ; 25.2 \%$ chose not to reveal their undergraduate course. The second sample consisted of 236 participants (women $=52.5 \%$ ) who were either currently enrolled in college or had already graduated. All were Brazilians and living in Brazil at the time of data collection. Their ages ranged from 18 to 37 years $(\mathrm{M}=23.62, \mathrm{SD}=4.59)$.

\section{Instruments}

Brazilian version of the Smartphone Addiction Scale (SAS-BR)

The SAS-BR is the Brazilian version of the original SAS. ${ }^{5}$ This self-report measure consists of 33 items, each of which requires responses to be recorded on a six-point Likert scale ( 1 = strongly disagree; 6 = strongly agree). Composite scores can range from 33 to 198 points, and higher scores are indicative of higher levels of problematic behaviors related to smartphone use. Dr. Min Kwon, who was the first author of the published version of the original SAS, authorized us to translate and adapt the SAS for use with Brazilian samples.

Translation of the SAS into the Portuguese language was undertaken by two translators. All questions subsumed by the English version of the SAS were sent to a professional translator who undertook the first translation of the items. Next, the scale was sent to a second translator who checked for correctness of terminology and agreement between the original and translated versions of the text. Finally, a back-translation was carried out, and a compatibility rate of approximately $80 \%$ was found. ${ }^{19}$ The SAS-BR is presented in Table S1, available as online-only supplementary material. 


\section{Personal information questionnaire}

A personal information questionnaire was created by the authors. It consisted of questions that required demographic information such as age, gender, and major (if the participant was currently enrolled in a course).

\section{Procedures}

\section{Data collection}

Chain sampling was used to recruit participants from social networks. The participants were invited to the Laboratório de Neurociência Cognitiva e Social, Universidade Presbiteriana Mackenzie. In the laboratory, they completed the personal information questionnaire and SAS-BR in the presence of the researchers. Upon completion, the participants who were currently enrolled in colleges received course credits as compensation for their participation.

\section{Data analysis}

Mahalanobis distance analysis was used to identify outliers. Participants with a resultant probability value that was lower than 0.001 were excluded from the sample. ${ }^{20}$ The Kaiser-Mayer-Olkin (KMO) test and Bartlett's test of sphericity served as tests of sampling adequacy, and the results were used to examine the factorability of the data. Descriptive statistics (M, SD, and frequencies) were also computed for all study variables.

Since the items were answered on a rating scale, a polychoric matrix was used as the input for this analysis. Subsequently, parallel analysis ${ }^{21}$ was conducted to explore the maximum number of dimensions that undergirded the data. Next, an unrestricted factor analysis was conducted to examine the pattern of loadings for each observed variable and determine the internal structure of the SASBR. Models that entailed one to six factors were tested and compared using classical factor analytic approaches, with principal axis factoring as the extraction method and maximum likelihood analysis with oblimin rotation as the estimation method.

In addition to this classical analytic approach, an item factor analysis (IFA) was implemented by using E-MIRT analysis. The IFA models are mathematically equivalent to classical factor analysis, ${ }^{22}$ but with another parametrization. Some advantages of IFA models include the use of full information estimates, the use of goodness-of-fit assessment, the option to use factor analysis rotations, and the incorporation of both unrestricted and restricted model specification; furthermore, the E-MIRT incorporates the advantages of item response theory framework for categorical responses data. ${ }^{23,24} \mathrm{~A}$ graded response model $^{25}$ with Metropolis-Hastings Robbins-Monro hybrid (MH-RM) algorithm estimation and Newton-Raphson optimizer fit the data well. All the analyses were conducted using $\mathrm{R}^{26}$ and the psych, ${ }^{27}$ lavaan, ${ }^{28}$ and mirt $^{29}$ packages. Model fit was evaluated using $\mathrm{M}^{*}$, the chisquared comparison index, which is suitable for use with long tests that consist of items that yield polytomous data $^{30}$; the comparative fit index (CFI); Tucker-Lewis index (TLI); and root-mean-square error of approximation (RMSEA).

The solution was chosen by aggregating the results from all the exploratory approaches and was checked by a restricted factor analysis approach. Thus, a confirmatory factor analysis with weighted least squares means and variance (WLSMV) adjusted estimation and SatorraBentler scaled test were conducted. The fit of the model was evaluated in terms of a robust CFI, TLI, standardized root mean square residual (SRMSR), and RMSEA. The reliability of the SAS-BR and factors that were yielded by these analyses were tested by computing McDonald's omega and Cronbach's alpha coefficients. We chose to present the two coefficients because past research used both, and we wanted to present results comparable with past research findings.

The thresholds that we considered for the model fit indices are: CFI $>0.95,{ }^{31} \mathrm{TLI}>0.95,{ }^{31}$ SRMSR $<$ $0.08,{ }^{31}$ and RMSEA $<0.06 .^{31}$ Additionally, we used a threshold value of 0.30 for factor loadings ${ }^{32}$ and a value of 0.60 for internal consistency coefficients. ${ }^{33}$

\section{Ethics statement}

This study was conducted in accordance with the recommendations of the ethics committee of research at the Universidade Presbiteriana Mackenzie (CAAE 98608718. 0.0000 .0084 ) and Declaration of Helsinki. All the participants provided written informed consent.

\section{Results}

Mahalanobis distance analysis revealed that 14 participants had a distance probability value that was lower than 0.001; therefore, they were excluded from the sample. The KMO test of sampling adequacy yielded a value of 0.915 , while Bartlett's test for sphericity yielded a significant result, $\chi_{(528)}^{2}=5,021.13, p<0.001$. The mean score obtained by the participants on the SAS-BR was 97.13 $(S D=25.91$, median $=96.50)$. Parallel analysis revealed that a maximum of six factors undergirded the data; each of these models was further explored.

As a first step, the unrestricted factor loadings of the models that consisted of one to six factors were evaluated. Both the six- and five-factor models yielded acceptable fit indices (RMSEA $_{6 \text {-factor }}=0.05$ [confidence interval \{Cl 0.04-0.05], $\mathrm{RMSR}_{6 \text {-factor }}=0.03$; $\mathrm{RMSEA}_{5 \text {-factor }}=0.06$ $\left[\mathrm{Cl} 0.05-0.06\right.$ ], $\mathrm{RMSR}_{5 \text {-factor }}=0.04$ ) and explained $53 \%$ and $50 \%$ of the variances, respectively.

Both solutions were also investigated by E-MIRT analysis. Neither model yielded good fit indices for all 33 items. Furthermore, items 11, 13, 20, and 24 exhibited the worst fit indices and were therefore excluded from subsequent analyses. The five-factor model, which was extracted using oblimin rotation, yielded good fit indices $\left(\mathrm{M} 2^{*}=\right.$ 174.72, degrees of freedom $[\mathrm{df}]=155, \mathrm{p}=0.132, \mathrm{RMSEA}=$ 0.019 [Cl 0.00-0.03], SRMSR $=0.03, \mathrm{TLI}=0.98, \mathrm{CFI}=$ 0.99). Item loadings that were larger than 0.30 are presented in Table 1, and intercorrelations among the factors are presented in Table 2. One item (19) did not load onto any dimension, whereas three items $(10,12,22)$ 


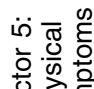

这

受

$\ddot{\forall}$ 을

造 을

के

iे

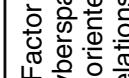

는 $\frac{\pi}{0}$

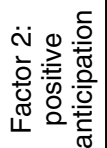

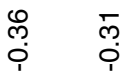

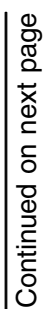

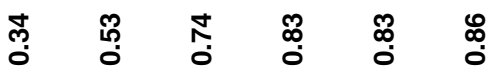

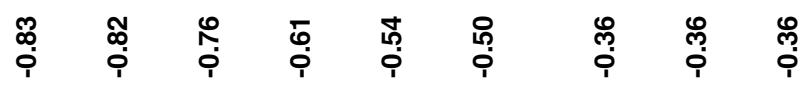

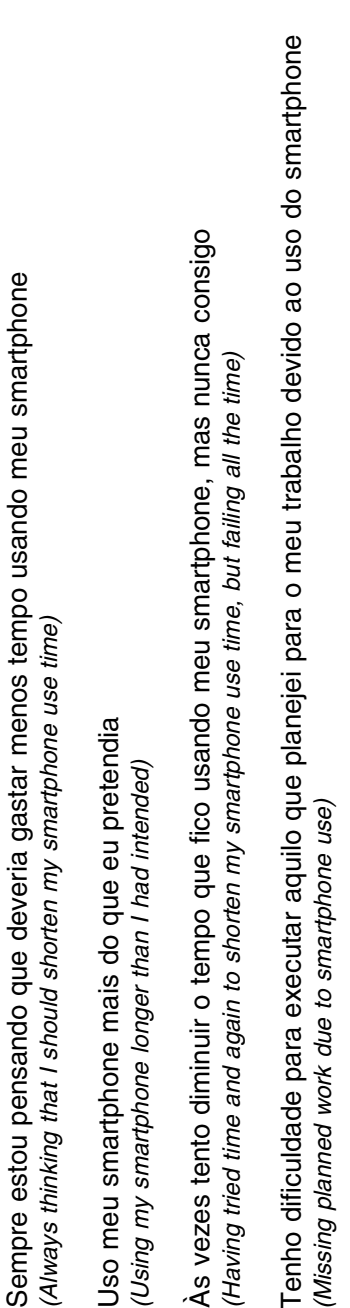

这

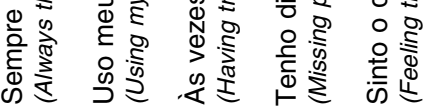

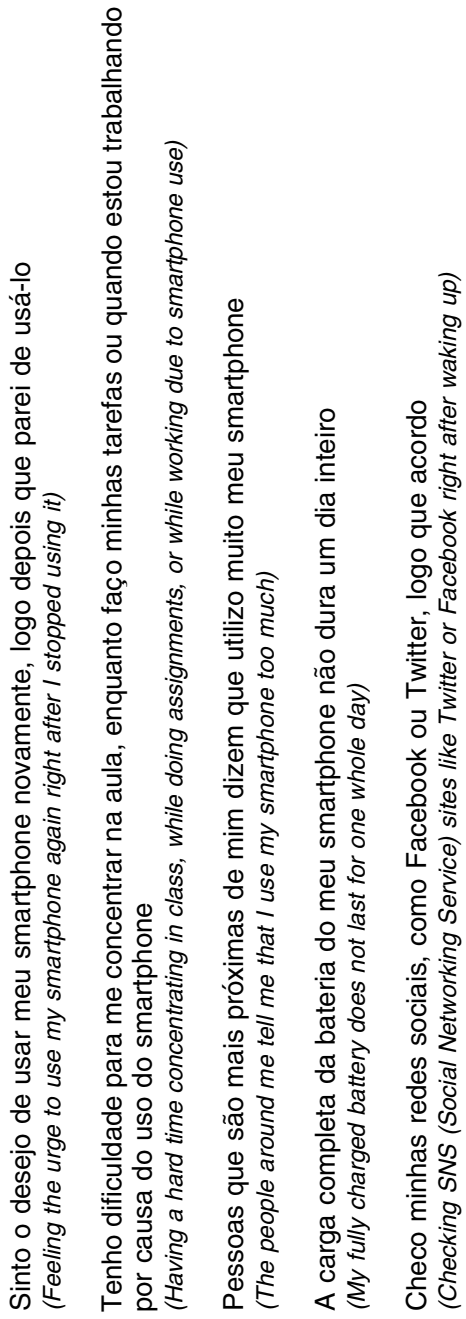

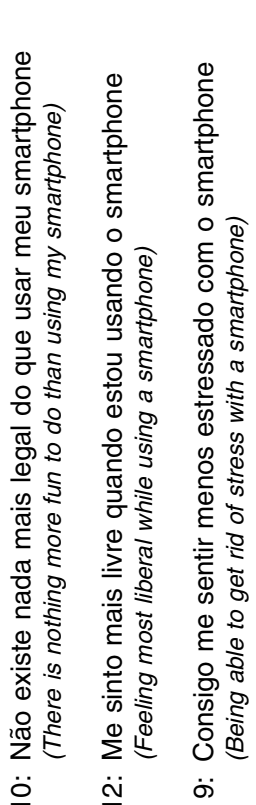

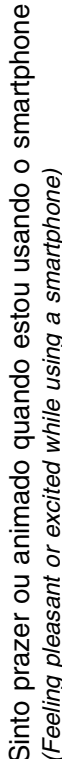

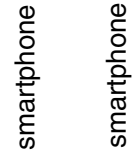
$\circ$ ญ 震 需

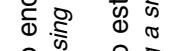

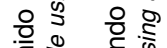
등 \begin{tabular}{lll}
$\pi$ & & 0 \\
0 & 0 & 0 \\
\hline
\end{tabular} हैं के कृ

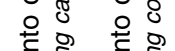
के $\frac{5}{4}$ 


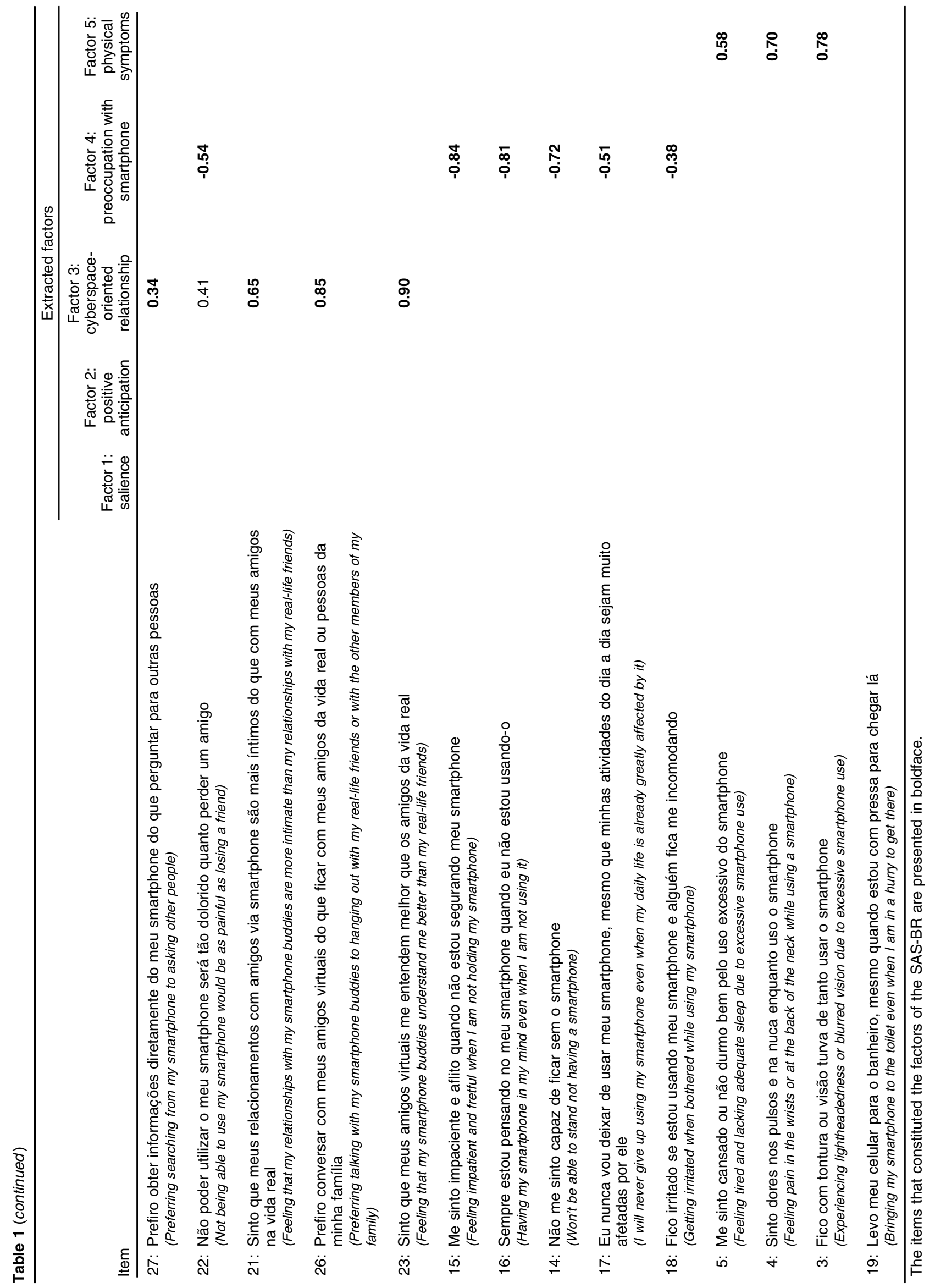


Table 2 Intercorrelations among the five factors yielded by factor analysis of the Brazilian version of the Smartphone Addiction Scale (SAS-BR)

\begin{tabular}{lcccc}
\hline & \multicolumn{3}{c}{ Extracted factors } \\
\cline { 2 - 5 } Factor & Factor 1 & Factor 2 & Factor 3 & Factor 4 \\
\hline Factor 1: salience & 1 & -0.333 & -0.175 & 0.461 \\
Factor 2: positive anticipation & & 1 & -0.495 & -0.350 \\
Factor 3: cyberspace-oriented relationship & & 1 & -0.329 & 0.185 \\
Factor 4: preoccupation with smartphone & & & 1 & -0.260 \\
Factor 5: physical symptoms & & & 1 \\
\hline
\end{tabular}

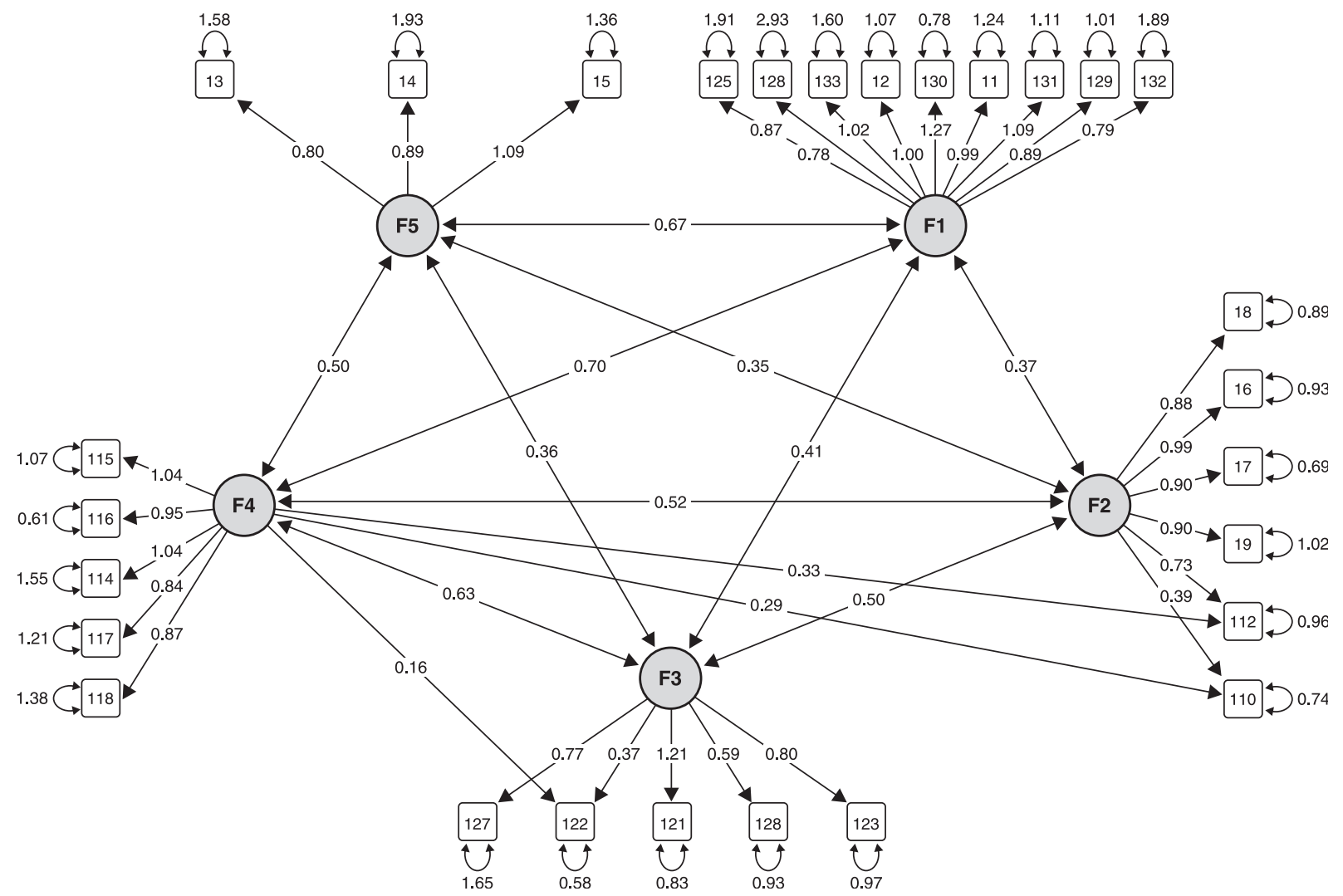

Figure 1 Structure of the model that was tested using confirmatory factor analysis. F1 = Salience; F2 = positive anticipation; F3 = cyberspace-oriented relationship; F4 = preoccupation with smartphone; F5 = physical symptoms; I = item .

cross-loaded onto two dimensions. An alternative model was developed. Each item was expected to load onto its corresponding dimension, but items 10, 12, and 22 were allowed to cross-load onto two dimensions. The global fit index was indicative of poor model fit. Therefore, a consolidated five-factor solution was chosen as the best fit for the data.

To test the replicability of the emergent five-factor structure, a restricted factor analysis was conducted using confirmatory factor analysis of the data obtained from the second sample. The fit indices were found to be satisfactory $(\mathrm{RMSEA}=0.064[\mathrm{Cl} 0.06-0.07], \mathrm{SRMSR}=$ $0.07, \mathrm{TLI}=0.97, \mathrm{CFI}=0.98$ ). Figure 1 shows the model that was tested using confirmatory factor analysis.

The internal consistency of the model showed an omega of 0.96 and an alpha of 0.93 . The reliability coefficient obtained for each factor is presented in Table 3.

\section{Discussion}

Parallel analysis revealed that the SAS-BR is undergirded by a maximum of six factors. The factor loadings that were yielded by the unrestricted factor analysis suggested that the five-factor model was the best fit for the data. Past studies have shown that the structure of the SAS ranges from five to seven factors. ${ }^{5,8-12}$ In contradistinction to past findings that the factors of the original $\mathrm{SAS}^{5}$ explained $61 \%$ of variance, our emergent factors explained only $50 \%$ of variance.

The factors yielded by the exploratory analysis were similar to those reported for the Romanian ${ }^{12}$ and Turkish ${ }^{9}$ versions of the SAS. Specifically, the overuse and tolerance factors and a few items of the daily-life disturbances factor were subsumed by a new factor that we named "salience" (e.g., "Feeling the urge to use my smartphone again right after I stopped using it"). Some authors ${ }^{2,34}$ 
Table 3 Reliability coefficients for the five factors of the Brazilian version of the Smartphone Addiction Scale (SAS-BR)

\begin{tabular}{|c|c|c|c|c|c|c|}
\hline Reliability coefficient & $\begin{array}{l}\text { Factor 1: } \\
\text { salience }\end{array}$ & $\begin{array}{c}\text { Factor 2: } \\
\text { positive anticipation }\end{array}$ & $\begin{array}{l}\text { Factor 3: } \\
\text { cyberspace-oriented } \\
\text { relationship }\end{array}$ & $\begin{array}{c}\text { Factor 4: } \\
\text { preoccupation } \\
\text { with smartphone }\end{array}$ & $\begin{array}{l}\text { Factor 5: } \\
\text { physical } \\
\text { symptoms }\end{array}$ & Total scale \\
\hline Alpha & 0.88 & 0.88 & 0.82 & 0.89 & 0.76 & 0.93 \\
\hline Omega & 0.90 & 0.70 & 0.73 & 0.73 & 0.73 & 0.96 \\
\hline
\end{tabular}

have noted an activity gains salience when it is considered to be more important than other activities and when it dominates the mind of the individual who engages in it. Some of the items that belong to the positive anticipation factor of the original SAS constituted the same factor in the present study (e.g., "There is nothing more fun to do than using my smartphone"/"Não existe nada mais legal do que usar meu smartphone"). Accordingly, this factor was referred to as positive anticipation even in the present study. Similarly, some of the items that belong to the cyberspace-oriented relationship and withdrawal factors of the original SAS constituted the same factor in this study (e.g., "Preferring talking with my smartphone buddies to hanging out with my real-life friends or with the other members of my family"/"Prefiro conversar com meus amigos virtuais do que ficar com meus amigos da vida real ou pessoas da minha família"; and "Feeling impatient and fretful when I am not holding my smartphone"/"Me sinto impaciente e aflito quando não estou segurando meu smartphone, respectively"). The constitution of this factor was very similar to one of the factors that emerged for the Romanian version of the SAS. ${ }^{12}$ The physical symptoms factor that emerged in our study was reported for the Turkish, but not the Romanian, version of the SAS. ${ }^{9}$ This factor differs from the daily-life disturbances factor of the original SAS. It assesses physical symptoms that are caused by excessive smartphone use, and it consists of the following items: "Experiencing lightheadedness or blurred vision due to excessive smartphone use"/"Fico com tontura ou visão turva de tanto usar o smartphone" (item 3); "Feeling pain in the wrists or at the back of the neck while using a smartphone"/"Sinto dores nos pulsos e na nuca enquanto uso o smartphone" (item 4); and "Feeling tired and lacking adequate sleep due to excessive smartphone use"/"Me sinto cansado ou não durmo bem pelo uso excessivo do smartphone" (item 5).

Taken together, the factor structures of the different versions of the SAS that have been validated in western countries are similar to each other, but differ from those that have been reported for versions of the SAS that have been validated in Asian countries. This result furthers our understanding of cultural differences in the factor structure of the SAS, which in turn has implications for the cross-cultural generalizability of the findings that have been derived using the SAS.

The results of confirmatory factor analysis, which was conducted using data obtained from a second sample, supported the validity of the aforementioned factor structure of the SAS-BR. The resultant indices were similar to those yielded by unrestricted factor analysis. It is noteworthy that the sample from which data were obtained to conduct confirmatory factor analysis was composed of university students and graduates, who had a higher mean age and demonstrated greater variability in demographic characteristics. Thus, the findings serve as additional evidence that the five-factor solution of the SAS-BR is generalizable to different Brazilian samples.

On the basis of factor analytic results, three items were deleted from the SAS-BR as they may not be valid measures of the construct. Specifically, item 11 ("My life would be empty without my smartphone"/"Minha vida seria vazia sem o meu smartphone") is a measure of not only smartphone addiction/problematic smartphone use, but also life satisfaction; therefore, participants may find this item to be confusing. In other words, the absence of a smartphone may not have a significant effect on the life satisfaction of those who consider their lives to be metaphorically empty to begin with. Similarly, with regard to item 13 ("Using a smartphone is the most fun thing to do"/“Usar o smartphone é a coisa mais divertida para fazer"), smartphone use may be the most fun activity that is available to those who do not have other fun activities to engage in. In this regard, these items may be stronger measures of life satisfaction and the availability of fun activities in which to engage than of smartphone use. Additionally, item 24 ("Constantly checking my smartphone so as not to miss conversations between other people on Twitter or Facebook"/"Constantemente checo meu smartphone para não perder nenhuma conversa entre outras pessoas no Twitter ou Facebook") was also deleted because it assessed addiction to or the maladaptive use of the corresponding social networking services, rather than problematic smartphone use. However, item 25 ("Checking SNS [social networking service] sites like Twitter or Facebook right after waking up"/"Checo minhas redes sociais, como Facebook ou Twitter logo que acordo"), which also pertains to social networking services, was not deleted. Therefore, the results that pertain to this item must be interpreted with caution. Finally, item 19 ("Bringing my smartphone to the toilet even when I am in a hurry to get there"/ "Levo meu celular para o banheiro, mesmo quando estou com pressa para chegar lá") did not load onto any factor. As the toilet is one of the most common places in which Brazilians use their smartphones, ${ }^{35}$ this item may not be an adequate indicator of problematic smartphone use among Brazilians.

Additionally, three items cross-loaded onto two factors (Table 1). Specifically, item 10 ("There is nothing more fun to do than using my smartphone"/"Não existe nada mais legal do que usar meu smartphone") cross-loaded onto the positive anticipation and preoccupation with smartphone factors. We chose to include this item in the 
positive anticipation factor based on the theoretical framework of the scale. Indeed, this item assesses the positive thoughts that are associated with smartphone use, and it was designed to measure positive anticipation in the original SAS. ${ }^{5}$ Thus, we included item 10 in the positive anticipation factor rather than the preoccupation with smartphone factor. Furthermore, item 12 ("Feeling most liberal while using a smartphone"/"Me sinto mais livre quando estou usando o smartphone") also cross-loaded onto the positive anticipation and preoccupation with smartphone factors. We chose to include this item in the positive anticipation factor because its content was similar to that of other items that loaded onto this factor. Indeed, this item was designed to assess positive anticipation in the original SAS. ${ }^{5}$ Finally, item 22 ("Not being able to use my smartphone would be as painful as losing a friend"/"Não poder utilizar o meu smartphone será tão dolorido quanto perder um amigo") cross-loaded onto the cyberspaceoriented relationship and preoccupation with smartphone factors. In the original SAS, this item is subsumed by the cyberspace-oriented relationship factor, ${ }^{5}$ but the item content does not appear to measure the intended construct. This item assesses whether the pain that is caused by the loss of a smartphone is perceived to be equivalent to the pain that is caused by the loss of a friend. Thus, participants who obtain high scores on this item are admittedly more concerned about the loss of their smartphones than participants who obtain low scores on this item. Since this item was considered to be a measure of preoccupation with smartphones, it was included in the respective factor. Furthermore, this item was subsumed by the preoccupation with smartphone factor of the Romanian version of the SAS. ${ }^{12}$

It is noteworthy that the SAS has demonstrated different factor structures in different countries. This suggests that the factor structure of the SAS is culturally variant, which may be explained by the fact that some items (e.g., 19) function differently in different cultures.

The factor loadings that emerged in this study were acceptable. The items that were included in the original SAS were selected using a cutoff score of 0.40 for factor loadings. In other words, items that had a factor loading that $<0.40$ were excluded. As a result, 15 items were excluded from the original SAS (the first version of the SAS consisted of 48 items). ${ }^{5}$ However, the other versions of the $S A S^{8-12}$ retained items with factor loadings $<0.40$. Accordingly, we chose to use a cutoff value of 0.30 for factor loadings; consequently, item 19 was excluded from the instrument.

It is noteworthy that we did not find any published reports of adaptation of the SAS for use in developed countries, such as the United States and England. Accordingly, the sample that was used in this study did not belong to western, educated, industrialized, rich, and democratic (WEIRD) countries, which are overrepresented in research studies in the field of social sciences. Therefore, it appears that the SAS is emerging as a valid scale that is suitable for use across various non-WEIRD countries.

Past studies have reported distinct factor structures but consistent support for the reliability of the SAS ${ }^{12}$; similar trends were observed in the present study. The internal consistency of the scale, which was measured using McDonald's omega and Cronbach's alpha coefficients, was excellent. Additionally, four out of the five factors demonstrated acceptable to good reliability; one factor demonstrated moderate levels of internal consistency. The physical symptoms factor of the Turkish version of the SAS evinced a low $(\alpha<0.06)$ reliability coefficient. ${ }^{9}$ This may be attributable to the relatively younger age of the study participants. Specifically, younger participants may be healthier and experience lower levels of discomfort when they use their smartphones. Thus, these factors may explain the low internal consistency values that emerged for this factor.

It is noteworthy that although the validity of smartphone usage scales has been called into question, ${ }^{16}$ the items of the SAS show broadly similar structures in different countries and cultures. Furthermore, continued research into these scales and tests is important because the evidence gained in such studies is essential to understanding the nosology of non-established mental conditions. ${ }^{18}$

This study has a few limitations. First, the sample consisted primarily of university students. Therefore, future studies must focus on the general population if generalizability is to be achieved. Furthermore, we did not use any clinical measures of problematic smartphone use. Such measures allow one to examine ROC curves rather than merely rely on self-report measures. Moreover, in this study, we did not ascertain a cutoff score that could be used to identify individuals with problematic smartphone use in Brazil. This would have required us to either use a diagnostic instrument or employ a trained professional to individually interview and identify participants with problematic patterns of smartphone use. Therefore, future studies should aim to establish evidence of validity that supports score interpretation and to ascertain a cutoff score for the SAS-BR so that its clinical utility is augmented.

In conclusion, this study is the first to examine evidence of reliability of the long version of the SAS in a Brazilian sample. Our study aimed to examine the factor structure and internal consistency of the SAS-BR among university students. With regard to the first objective, we found a five-factor structure that was similar to those that have been reported for the Romanian ${ }^{12}$ and Turkish ${ }^{9}$ versions of the SAS. These findings underscore the similarities that are shared by the factor structures of the versions of the SAS that have been developed in western countries, and have important implications for the generalizability of results that are derived using the SAS. The factors that were identified in the present study were salience, positive anticipation, cyberspace-oriented relationship, preoccupation with smartphone, and physical symptoms. Confirmatory factor analysis, which was conducted using data obtained from a second independent sample, replicated the emergent five-factor structure. This finding suggests that it is possible that the factor structure of the SAS-BR can be generalized to different Brazilian samples, although more studies are needed. With regard to the second objective, the SAS-BR as a whole demonstrated strong reliability, whereas the five factors 
demonstrated strong to moderate levels of reliability. Thus, the SAS-BR can be considered a reliable measure of problematic smartphone use in Brazil. Studies focusing on evidence of validity for clinical samples and the relation between SAS and other tests are necessary for a better understanding of the quality of the measure and the extension of the interpretation that its scale provides. The emergent psychometric properties of the SAS-BR permit cautious use of this scale in clinical settings, which in turn may provide further insights into problematic smartphone use.

\section{Acknowledgements}

We thank Dr. Yuri Busin for his assistance with data collection. This study was supported by Coordenação de Aperfeiçoamento de Pessoal de Nível Superior (CAPES), Fundação de Amparo à Pesquisa do Estado de São Paulo (FAPESP; grant no. 2018/09654-7 and 2018/06039-0), and Conselho Nacional de Desenvolvimento Científico e Tecnológico (CNPq; grant no. 309453/2011-9).

\section{Disclosure}

The authors report no conflicts of interest.

\section{References}

1 Lin YH, Chang LR, Lee YH, Tseng HW, Kuo TB, Chen SH. Development and validation of the smartphone addiction inventory (SPAI). PLoS One. 2014;9:e98312.

2 Panova $T$, Carbonell $X$. Is smartphone addiction really an addiction? J Behav Addict. 2018;7:252-9.

3 Elhai JD, Levine JC, Dvorak RD, Hall BJ. Fear of missing out, need for touch, anxiety and depression are related to problematic smartphone use. Comput Human Behav. 2016;63:509-16.

4 Panova T, Lleras A. Avoidance or boredom: negative mental health outcomes associated with use of information and communication technologies depend on users' motivations. Comput Human Behav. 2016;58:249-58.

5 Kwon M, Lee JY, Won WY, Park JW, Min JA, Hahn C, et al. Development and validation of a smartphone addiction scale (SAS). PLoS One. 2013;8:e56936.

6 Chen B, Liu F, Ding S, Ying X, Wang L, Wen Y. Gender differences in factors associated with smartphone addiction: a cross-sectional study among medical college students. BMC Psychiatry. 2017;17341.

$7 \mathrm{Kim} \mathrm{HJ}$, Min JY, Kim HJ, Min KB. Accident risk associated with smartphone addiction: a study on university students in Korea. J Behav Addict. 2017;6:699-707.

8 Demirci K, Akgönül M, Akpinar A. Relationship of smartphone use severity with sleep quality, depression, and anxiety in university students. J Behav Addict. 2015;4:85-92.

9 Demirci K, Orhan H, Demirdas A, Akpinar A, Sert H. validity and reliability of the Turkish version of the smartphone addiction scale in a younger population. Klinik Psikofarmakol Bülteni. 2014;24:226-34.

10 Ching SM, Yee A, Ramachandran V, Sazlly Lim SM, Wan Sulaiman WA, Foo YL, et al. Validation of a Malay version of the smartphone addiction scale among medical students in Malaysia. PloS One. 2015;10:e0139337.

11 Sfendla A, Laita M, Nejjar B, Souirti Z, Touhami AA, Senhaji M. Reliability of the Arabic smartphone addiction scale and smartphone addiction scale-short version in two different Moroccan samples. Cyberpsychol Behav Soc Netw. 2018;21:325-32.

12 Vintilă M, Tudorel OI, Goian C, Bărbat C. Determining the structure of smartphone addiction scale: a bifactor model analysis. Curr Psychol; 2018. doi: 10.1007/s12144-018-0035-0

13 Newzoo. Top Countries Smartphone Users [Internet]. 2018 [cited 2020 May 6]. https://newzoo.com/insights/rankings/top-50-countriesby-smartphone-penetration-and-users/

14 Mescollotto FF, Castro EM, Pelai EB, Pertille A, Bigaton DR. Translation of the short version of the smartphone addiction scale into Brazilian Portuguese: cross-cultural adaptation and testing of measurement properties. Braz J Phys Ther. 2019;23:250-6.

15 Sales HFS, Silva FMSM, Lima BDJL. Adaptação da escala de uso compulsivo de Internet para avaliar dependência de smartphone. Av Psicol Latinoam. 2018;36:155-66.

16 Ellis DA, Davidson BI, Shaw H, Geyer K. Do smartphone usage scales predict behavior? Int J Hum Comput Stud. 2019;130:86-92.

17 Ellis DA. Are smartphones really that bad? Improving the psychological measurement of technology-related behaviors. Comput Human Behav. 2019;97:60-6.

18 Blashfield RK, Keeley JW, Flanagan EH, Miles SR. The cycle of classification: DSM-I through DSM-5. Annu Rev Clin Psychol. 2014; 10:25-51.

19 Busin Y. Estado emocional e padrão de uso de redes sociais: desenvolvimento de instrumento e análise do efeito de emoções negativas na atribuição de valores financeiros e sentimentais [dissertation]. São Paulo: Universidade Presbiteriana Mackenzie; 2018.

20 Tabachnick BG, Fidell LS. Using multivariate statistics. 5th ed. Boston: Pearson; 2007.

21 Horn JL. A rationale and test for the number of factors in factor analysis. Psychometrika. 1965;30:179-85.

22 Wirth RJ, Edwards MC. Item factor analysis: current approaches and future directions. Psychol Methods. 2007;12:58-79.

23 Forero CG, Maydeu-Olivares A. Estimation of IRT graded response models: limited versus full information methods. Psychol Methods. 2009;14:275-99.

24 Mair P. Modern psychometrics with R Cham: Springer; 2018.

25 Samejima F. Estimation of latent ability using a response pattern of graded scores. Psychometrika. 1969;34:1-97.

26 R Core Team. R: a language and environment for statistical computing. R Foundation for Statistical Computing, Vienna, Austria [Internet]. 2019 [cited 2020 May 6]. https://www.R-project.org/

27 Revelle W. Psych: procedures for personality and psychological research [Internet]. Version $=1.8 .12 .2018$ [cited 2020 May 6]. https:// CRAN.R-project.org/package $=$ psych

28 Rosseel $Y$. lavaan: an $r$ package for structural equation modeling [Internet]. 2012 [cited 2020 May 6]. http://www.jstatsoft.org/v48/i02/

29 Chalmers RP. Mirt: a multidimensional item response theory package for the R environment. J Stat Softw. 2012;48(6).

30 Cai L, Hansen M. Limited-information goodness-of-fit testing of hierarchical item factor models. Br J Math Stat Psychol. 2013;66:245-76.

$31 \mathrm{Hu}$ LT, Bentler PM. Cutoff criteria for fit indexes in covariance structure analysis: conventional criteria versus new alternatives. Struct Equ Modeling. 1999;6:1-55.

32 Hair JF, Tatham RL, Anderson RE, Black W. Multivariate data analysis. 5th ed. London: Prentice-Hall; 1998.

33 Fabrigar LR, Wegener DT, MacCallum RC, Strahan EJ. Evaluating the use of exploratory factor analysis in psychological research. Psychol Methods. 1999;4:272-99.

34 Griffiths M. A 'components' model of addiction within a biopsychosocial framework. J Subst Use. 2005;10:191-7.

35 Nielsen Holding N.V (NYSE: NLSN). Brasileiros com internet no smartphone já são mais de 70 milhões [Internet]. 2015 Sep 14 [cited 2019 Jun 6]. https://www.nielsen.com/br/pt/press-room/2015/Brasi leiros-com-internet-no-smartphone-ja-sao-mais-de-70-milhoes.html 